\title{
FESTSCHRIFT
}

\section{Methods and principles in biomedical ethics}

\section{T L Beauchamp}

J Med Ethics 2003;29:269-274

The four principles approach to medical ethics plus specification is used in this paper. Specification is defined as a process of reducing the indeterminateness of general norms to give them increased action guiding capacity, while retaining the moral commitments in the original norm. Since questions of method are central to the symposium, the paper begins with four observations about method in moral reasoning and case analysis. Three of the four scenarios are dealt with. It is concluded in the "standard" Jehovah's Witness case that having autonomously chosen the authority of his religious institution, a Jehovah's Witness has a reasonable basis on which to refuse a recommended blood transfusion. The author's view of the child of a Jehovah's Witness scenario is that it is morally required-not merely permitted-to overrule this parental refusal of treatment. It is argued in the selling kidneys for transplantation scenario that a fair system of regulating and monitoring would be better than the present system which the author believes to be a shameful failure.

Correspondence to: Professor T L Beauchamp, Kennedy Institute of Ethics, Georgetown University, 37 th and $O$ Sts, NW, Washington DC 20007, USA; beauchat@ georgetown.edu

Accepted for publication 8 July 2003
- irstly, Raanan Gillon and I share the view that it is legitimate and rewarding to diagnose cases through the lens of general ethical principles. I will here assume, rather than argue for, moral principles of respect for autonomy (the obligation to respect the decision making capacities of autonomous persons); non-maleficence (the obligation to avoid causing harm); beneficence (obligations to provide benefits and to balance benefits against risks), and justice (obligations of fairness in the distribution of benefits and risks). ${ }^{1}$ Methodologically, these principles function for me much as considered judgments function for John Rawls in his justly famous explication of the method of reflective equilibrium. ${ }^{2}{ }^{3}$ Like him, I believe that method in ethics begins with the moral convictions that inspire the highest confidence and that appear to have the lowest level of bias. They serve as first principles and conditions of more specific moral conceptions. ${ }^{4}$ I take these principles to be universally valid norms that warrant us in making intercultural and crosscultural judgments about moral depravity, morally misguided beliefs, savage cruelty, and other moral failures.

Secondly, these abstract principles need to be specified to make them suitable for the analysis of a context, case, or policy. ${ }^{56}$ Specification is a process of reducing the indeterminateness of general norms to give them increased action guiding capacity, while retaining the moral commitments in the original norm. Filling out the commitments of the norms with which one starts is accomplished by narrowing the scope of the norms. This process involves, as Henry Richardson puts it, "spelling out where, when, why, how, by what means, to whom, or by whom the action is to be done or avoided" (Richardson, ${ }^{5}$ p 289). Complex or problematic cases almost always involve contingent normative conflict, as do each of the cases in this symposium. The first line of attack in managing these cases should be to specify the relevant norms in order to eradicate the conflicts among them. This method requires, as does the associated method of reflective equilibrium, that we match and adjust all of our well substantiated moral judgments in order to render them coherent with the full range of our moral commitments. $^{78}$

Thirdly, I accept the casuistical postulate that leading cases (so called "paradigm cases") often become enduring and authoritative sources of reflection and decision making. Past decisions about moral rights and wrongs in cases serve as a form of authority for decisions in new cases. These cases profoundly influence our standards of fairness, negligence, justified paternalism, and the like. In this way, analogical reasoning links past cases to present cases. ${ }^{9-11}$ Analogical reasoning of this sort requires that there be normative similarities across cases. The casuistical method therefore assumes that general norms of moral relevance couple the cases. ${ }^{12}$ That is, all analogical reasoning in ethics requires a connecting norm in order to show that one object or event is like or unlike another in the relevant respects. The creation or discovery of these circumstance linking norms cannot be achieved purely by analogy. At least rough and ready principles, rules, or maxims are required. For this reason, casuistry is not a rival methodological model to the use of principles and specification, even though they have been widely regarded in the literature of ethics as conflicting methods.

Fourthly, styles of case analysis are legitimately diverse. Different disciplines and different goals of case analysis will direct a reader to identify specific elements in the cases as deserving of analytical development. There is no reason to suppose that moral philosophy or methods of specification supply the only way or the best way to treat a case. From this perspective, there may be no single right solution to the problems presented in a case, but it does not follow that morally unjustified and poorly reasoned answers are beyond valid criticism.

To conclude these comments on method, I am assuming that very general moral principles are shared by all moral persons, but that specified 
moral frameworks (those that moral agents likely bring to and develop in case analysis) are works in progress that can legitimately vary from person to person and from culture to culture. These specified moralities include the many moral norms, aspirations, ideals, attitudes, and sensitivities that spring from cultural traditions, religious traditions, professional practice, institutional codes of ethics, and the like. The general moral standards shared by all moral persons are conspicuously abstract, universal, and content thin. Particular moralities are usually the reverse: concrete, non-universal, and content rich.

Frameworks of particular moralities are not finished products. Solutions to moral problems, such as whether and how to respect religious beliefs and how to develop the most suitable system for organ procurement and distribution, are projects periodically in need of adjustment by further specification and the search for reflective equilibrium. We should assume that, in the analysis of hard cases, we face a never ending search for coherence and for solutions to new problems that may challenge our prevailing moral convictions.

With these observations about method behind us, I turn to the three scenarios.

\section{THE "STANDARD" JEHOVAH'S WITNESS CASE}

The now standard treatment of the "standard" case in the first scenario is to specify the commitments of the principle of respect for autonomy for those contexts in which the religious commitments of a patient conflict with the healing commitments of health care professionals or institutions. ${ }^{13}$ To look for an appropriate specification in the case before us, consider two moral rules that have come into conflict in this first scenario:

1. It is morally prohibited to risk death for a patient whose life threatening condition can be medically managed by suitable medical techniques.

2. It is morally prohibited to disrespect a first party refusal of treatment.

In a wide variety of cases-well beyond those involving religious commitments-patients refuse promising treatments offered by medical officials. Sometimes these patients are concerned about the consequences of treatment, but often their decisions rest on principled convictions or specific objectives that exhibit little or no concern with medical consequences. For example, these patients may not find the treatment worth the cost, may not trust their doctors, may wish to die, or may have religious objections to an intervention.

To handle conflicts between the obligation to treat and the obligation to respect a refusal, it is now widely accepted that rule 2 should be specified as follows in order to handle the problem of a contingent conflict with rule 1 :

2.1. It is morally prohibited to disrespect a first party refusal of treatment by a patient, unless the refusal is nonautonomous and presents a significant danger to the patient.

Rule 2.1 qualifies as a specification because much of the content of the original rule (2) remains intact. Rule 2.1 states that a physician is not absolutely required to respect refusals of treatment, but that the range of exceptions is narrow. This rule has the simple but powerful effect of informing medical officials (indeed, everyone) that all truly autonomous refusals of treatment must be respected, no matter the consequences.

There is no evidence in the scenario before us to indicate that the patient has made other than an autonomous choice, though nothing in this case indicates whether the choice by the patient was adequately autonomous. Some moral philosophers have argued that autonomous action is incompatible with the authority of religious organisations and political communities that legislate persons' principles and decisions. They maintain that autonomous persons must act on their own reasons and can never submit to the dictates of religious or political authorities. ${ }^{14-16}$ No fundamental inconsistency exists, however, between autonomy and authority if individuals exercise their autonomy in accepting the norms of the authority. Having autonomously chosen the authority of his religious institution, a Jehovah's Witness has a reasonable basis on which to refuse a recommended blood transfusion.

However, rule 2.1 may not be quite as unbending as my analysis thus far suggests. Occasionally in medical ethics, an autonomy interest is minimal and a medical benefit maximal, warranting a paternalistic intervention by the physician. Justified paternalism of this sort constitutes another type of exception to rule 2. This exception is limited, however, to cases in which a vital or substantial autonomy interest is not at stake. This is not the case in the present scenario. The decision by this Jehovah's Witness rests on a paradigmatically vital autonomy interest. To intervene coercively by compelling a transfusion could not be justified under any plausible condition of justified paternalism known to me.

Once the questions I have raised about autonomy are settled, this case does not otherwise turn on an assessment, by the patient or others, of harms and benefits to the patient. The patient's assessment is not concerned with medical benefits and harms, and it distorts the logic of the agent's reasoning to suggest that there are religious harms and benefits at stake. It is also unlikely that the patient is taking into account his psychological suffering.

This case also does not turn on principles of justice. Any rights at stake are rights of autonomy, not rights grounded in distributive justice. There is potentially a justice connected question about the legitimacy of using more expensive materials (non-blood products) in place of less expensive and more efficacious products. But absent further development of this consideration of justice-a task that well exceeds the possibilities of the present symposium-this case does not turn on issues of justice.

\section{THE CHILD OF A JEHOVAH'S WITNESS CASE}

In the second scenario, parents committed to the Jehovah's Witness faith refuse a blood transfusion for their two year old child.$^{13}$ The surgeon and the hospital lawyer resist this decision and propose to use their own authority to override the authority of the parents. The following two rules conflict in this second scenario:

1. It is morally prohibited to risk death for a patient if his or her life threatening condition can be medically managed by suitable medical techniques.

2. It is morally prohibited to disrespect a parental refusal of treatment.

In many circumstances, beyond but including those involving religious commitments, parents refuse treatment for infants in the conviction that the infant's overall best interest is served. To handle such conflicts, rule 2 can be specified as 2.1:

2.1. It is morally prohibited to disrespect a parental refusal of treatment, unless the refusal constitutes child abuse, child neglect, or violates a right of the child.

Rule 2.1 qualifies as a specification because much of the content of the original rule remains intact, but now we understand that a medical professional is only generally required to respect parental refusals of treatment. Rule 2.1 is a start, but only a start, down the path of specification. It will not handle all cases and will need further examination of child abuse, child endangerment, child neglect, and the rights of children. None the less, 2.1 does show that there is a path out of the initial conflict between rules 1 and 2, and it indicates that physicians and hospital administrators are not confronted with an absolute rule requiring that medical officials uphold parental refusals. With enough additional specification, an entire hospital policy could be constructed that is 
generally adequate to process the range of cases of parental refusal that surgeons, paediatricians, and those in other specialties might expect to see.

Assuming that 2.1 is an acceptable specification, what action should be performed in the second scenario? My view is that it is morally required-not merely morally permitted-to overrule this parental refusal of treatment, because the refusal does constitute a form of child abuse, child endangerment, child neglect, or inattention to the rights of the child. Many forms of neglect, abuse, and endangerment of children have occurred in the name of religion, and withholding a recommended medical therapy on the basis of religious convictions, causing a child's preventable death, is one of them.

Jehovah's Witness parents who refuse lifesaving blood transfusions for their minor children have been widely considered in bioethics as a paradigm of overreaching parental authority. I accept this conclusion myself, but it must also be acknowledged that this judgment is not free of controversy. Legislative bodies around the world have, over the course of the last century, wavered and reversed themselves over these issues. They have, on the one hand, passed statutes that allow for so called "religious exemptions" that permit parental religious convictions to prevail over recommended medical treatment. But when parents then make judgments that endanger children, many of these legislatures temper or rescind the very religious exemptions they previously allowed. ${ }^{17}$

In 1944 the United States Supreme Court decided, in the case of Prince $v$ Massachusetts, ${ }^{18}$ that a Jehovah's Witness parent could not neglect the education of her nine year old child by dictating that the child sell religious magazines on the street. In this case, Ms Prince argued that her religious beliefs were constitutionally protected, but the Supreme Court found that rights of religion are not beyond limitation and that a child cannot reasonably be subjected to a poor education, to communicable disease, to ill health, or to death. The court determined that parents may martyr themselves, but may not martyr their children.

Prince established in US law an important principle that should be no less pronounced in morals, namely that religious standards and practices must yield to sober medical judgment when they seriously affect the welfare and health of children. Nothing in the protection of religious belief, in law, or in morals, should allow for the neglect of a child's appropriate medical treatment. More specifically, if a child faces a risk of death, disfigurement, serious bodily injury, or ill health a decision to withhold medical care constitutes parental abuse or neglect even if the parent's reason is religious and reflective of the parents' considered viewpoint.

We all recognise that rights of parental autonomy often appropriately prevent governments from intervening in the rearing of a child. Likewise, we recognise that an overarching interest of the child must be at stake to warrant government intervention. But parents who are committed to the view that medical treatment is sinful or will condemn a child to eternal damnation are particularly serious dangers to the welfare of their children. It is difficult, in law and morals, to protect both parents and children through a provision of religious exemptions from prosecution.

It is unclear why religious conviction stands as a special form of belief, somehow deserving a more protected status than moral, political, or aesthetic convictions. No less clear is why we should allow the religious convictions of a particular religious group to deserve a protected status. Why should the views of a denomination, such as Jehovah's Witness, be more protected than those same views when embraced by an individual who is not associated with this (or any other religious) denomination? A parent could make a judgment about what he or she accepts as religiously proscribed medical treatment even if no article of faith held by a religious group such as Jehovah's Witnesses stood behind the judgment.
I am pondering how we can distinguish bizarre and unprotected religious convictions (such as messianic views held by serial murderers) from those that are not bizarre and that merit protection, conventionally the religious mainstream. If we determine that legitimate parental decisions are confined to those based on the beliefs of established denominations, then a parent who is a member of a religious group other than one that accepts the creed in question could potentially be charged with involuntary manslaughter or neglect for the same action and the same religious conviction as that tolerated in support of a Jehovah's Witness parent. In short, I am raising sceptical questions about whether there could be a clear statute or moral rule that distinguished justifiable from unjustifiable parental decisions based on religious doctrine.

Parental rights have seldom been regarded in the law of Western nations as a legal trump. The widely recited language of parens patriae was not introduced in law to support parental rights; to the contrary, it was introduced to protect children against abusive parents. It literally means "parent of the country" and refers to the sovereign power of guardianship over those who cannot protect themselves. ${ }^{19}$ The doctrine supports state interventions to limit those actions of parents that breach parental responsibilities to protect a child.

Well before autonomy and privacy were pervasively applied through law and morals to the decisions of surrogates for incompetents and minors, the best interests standard-rather than an autonomy standard-was recognised as having authority over parental rights. It is the fitting standard for analysis of the case before us. The best interests standard validly overrides parental rights of control whenever the welfare interest of the child is substantial. If the interests of the child were less than substantial-for example, if the outcome of a surgical intervention had merely the effect of an unobtrusive scar-then deference to parental wishes would be reasonable. But the case before us indisputably involves a major interest of the child.

When parents bring a child to a physician for treatment, the physician's primary responsibility is to serve the child's interests even if the parents initiated the contract and even if the physician has obligations of fidelity to the parents. The latter obligations may be set aside if parental decisions seriously threaten a child's health or survival. Jehovah's Witnesses who reject blood transfusions for themselves have moral warrant for what they do only because their own autonomy gives them authority over themselves; they lose this authority if they reject medically necessary blood transfusions for their children. Accordingly, the surgeon in this case has made the correct choice.

The conclusions I have reached also apply to analogous contexts of surrogate decision making that involve vulnerable and incompetent adult patients. A useful rule to restrict all surrogate decision making is this: If a designated surrogate makes a decision that threatens the patient's best interests, the decision should be overridden unless there is an explicitly worded document executed by the incapacitated patient that supports the surrogate's decision. Such a document requires that a once competent patient stated a treatment preference in an advance directive. There is no such document in the case before us and therefore this exceptive rule does not apply.

I am arguing that there is no relevant difference between the situation of a vulnerable child whose parents impose their religious views and the situation of vulnerable adults whose surrogates impose their religious views. Consider-for example, both (1) adult patients who have no religious preferences and (2) adult patients who have stated religious preferences that clash with those of a surrogate. I take, as morally basic in both cases, that health care officials should, in circumstances of serious medical need, override the preferences of surrogates who use their religious convictions rather than a best interests standard. If we accept the validity of overriding surrogate decisions in these circumstances with adults, then moral 
coherence compels us to accept the validity of overriding parental judgments in relevantly similar circumstances.

\section{SELLING KIDNEYS FOR TRANSPLANTATION}

I turn now to the third scenario-selling kidneys. ${ }^{13}$ Here a distinction between the justification of policies and the justification of acts is needed. Public rules or laws sometimes justifiably prohibit conduct that is morally justified in individual cases. To put this distinction to work for present purposes, two moral questions about selling kidneys need to be distinguished: (1) Are persons ever morally justified in complying with requests that they sell one of their kidneys, and (2) Is there an adequate moral basis to justify the legalisation of a market in kidneys? As important as legalisation is, questions about the justifiability of individual acts present the more fundamental moral issue.

It is not difficult to construct circumstances of a contract between consenting adults in which it is morally permissible to sell one's kidney. Suppose that my wealthy cousin will perish without a kidney; he offers me $\$ 100000$ for mine. I am well informed about the current and lifetime risks of nephrectomy, and I could put the $\$ 100000$ to good use in reducing a burdensome mortgage. I understand my cousin well, and he understands me equally well. Limitation of our liberty would require a compelling justification for preventing us from entering into a relationship that will benefit me financially and will save his life. I see no reason why, judged as an individual act, it would be morally wrong of me to sell my kidney to my cousin.

I have thus far assumed that no considerations external to my relationship to my cousin, such as the implications of a worldwide market, are pertinent to a judgment of moral permissibility. Of course, other considerations may turn out to constitute good and sufficient moral reasons for banning the sale of kidneys as a matter of public law. One of the problems with the literature on a market in organs is that many different assumptions are made: some authors assume or argue for an open market, others a heavily regulated market; some authors presume a Third World source of the organs, whereas others do not consider international markets. Some authors make a distinction between receiving payment for and purchasing a kidney, whereas others make no such distinction. Some authors consider only monetary incentives (such as reimbursement for funeral expenses), not payments, whereas others see no morally relevant differences between incentives and payments. ${ }^{20-23}$

I cannot carefully consider the moral relevance of these important distinctions, but I will argue both that some policies that allow for sales and incentives are morally problematic and that, notwithstanding their problematic features, monetary inducements may still be justified. Although there are serious moral objections to some markets and incentives, these objections are not necessarily sufficient, I will argue, to warrant a ban on these inducements.

In $1999 \mathrm{CNN}$ reported that online shoppers who visited the internet auction site eBay were surprised to find a "fully functional kidney" for sale by a man giving his home as "Sunrise, Florida". He was proposing to sell one of his two kidneys. The price had been bid up before eBay intervened and terminated the (illegal) auction. ${ }^{24}$ It was not known whether this auction was genuine or to whom the kidney may have belonged, yet this auction was largely in public view. A private market in kidneys would be more difficult to monitor and to control, and therefore more problematic.

Countries in which markets in kidneys have flourished support this estimate. One study showed, after locating 305 sellers of kidneys in India, that persons who sold their kidneys generally worsened rather than bettered their financial position as a result of the sale, that some men forced their wives to sell a kidney, and that many sellers suffered a decline in health status. The selling of a kidney in India has not worked as a deliverance from indigence. This study shows (1) that for $96 \%$ of those who sell kidneys most of the money received was spent to pay off debts $(60 \%)$, to buy food and clothing $(22 \%)$, or for marriage $(5 \%) ;(2)$ that a person's poverty was more likely to be worsened than diminished after the sale of a kidney, and (3) that the money paid was not adequate to bring sellers out of debt. Of participants, $79 \%$ said that they would now not recommend selling a kidney. ${ }^{25}$ A second study in India indicates that sales of kidneys generally do not occur as a planned passageway from poverty to security, but rather function as a way of raising money to pay off high interest loans. ${ }^{26}$ As is well known in even Western countries, high interest loans (such as those in the automobile title pawn industry in the US) prey on the poor and undereducated who are caught in a never-ending cycle of borrowing and repaying.

Selling or purchasing a kidney need not involve disrespect for persons and is not in itself grounds for moral repulsion or indignation. What, then, is problematic? The worry most consistently expressed in literature on kidney sales is that markets invariably lead to some form of exploitation. This literature is, however, less than clear about the nature and conditions of exploitation. I will now consider what I take to be the two most worrisome problems.

\section{Exploitation deriving from systemic injustice}

Firstly, a market in kidneys may be unjust. This is not an issue of whether volunteers are paid a fair price. The question is whether free market distribution constitutes a fair system. A systemic injustice seems to me to occur if the gift of life through kidney transplantation benefits only the well off, with the burdens allocated entirely or disproportionately to disadvantaged members of society. Potentially a market in kidneys will produce a social situation in which virtually all kidney "donations" come from the poor, with the rich enjoying the availability of kidneys and escaping responsibility for donation (to relatives or to anyone). The limited financing currently available in many national health care systems would assure that transplantation is available only to the wealthy. (In India even long term dialysis is not available to the poor.) It seems to me unjust to allow and even encourage donation and selling in a circumstance in which those who donate or sell are blocked from receiving an organ when they themselves are in need. Distributive justice calls for more than libertarian exchange.

Organ donation has always been and should remain a social enterprise intended both to procure and to allocate a scarce resource in a broadly inclusive and participatory way. A market in kidneys has the potential of drawing a life giving resource exclusively from a narrow spectrum of willing and available "donors". This market is exploitative in the sense that the disadvantaged are used to the gain of the wealthy in the absence of a more general system of fair procurement and fair allocation. Many topics in bioethics beyond organ donation present similar problems-for example, the selection and payment of research subjects. Such issues can be addressed only by specifying and defending the precise conditions under which either an arrangement or a market is unfair-a task far beyond the scope of this article. This task would require that we take account of the justice of background conditions that cause circumstances of disadvantage, no less than constructing a fair system of procurement and allocation. To my knowledge, no one has as yet supplied a convincing account of unjust background conditions.

\section{Exploitation deriving from constraining situations}

A second problem of exploitation is that potential "volunteers" may be constrained by their situation into a nonvoluntary sale-that is, manipulated to the acceptance of offers because of the constraints of their impoverished condition. The issue here is not whether those who sell their kidneys 
are entirely free of manipulative or constraining influences, but whether they are sufficiently free so that they are enabled to act autonomously.

Rather obviously, a consent to the sale of one's kidney might not be sufficiently voluntary or informed to constitute an autonomous consent. Getting a potential volunteer to comprehend and appreciate risks and benefits can itself be a formidable task. For example, persons might not adequately appreciate the risk and nature of a deterioration in health status from nephrectomy, what the money they receive will purchase, the risks of a decline in family income, or the risk that a middle person or hospital will not make full payment. Potential volunteers may find the benefits overwhelmingly attractive, causing them to devalue the risks. In one respect, these volunteers correctly understand basic facts about procedures and arrangements, but, in other respects, their understanding is inadequate. The fact that $79 \%$ of participants in the study in India afterward said that they would not recommend selling a kidney suggests that if some persons who sell their kidneys had more information about likely consequences they would be less willing to sell.

As important as these issues of informed consent are, I will here set them aside in order to attend to the more salient and perplexing problem of constraining situations-sometimes misleadingly called coercive situations. For coercion to occur, one person must intentionally threaten another in order to gain compliance. Constraining situations, by contrast, are those in which non-intentional, coercion like situations cause a person to feel controlled by the constraints of a situation, rather than by the design of another person. People unintentionally cause other persons to feel "threatened," and sometimes situations such as illness, powerlessness, and lack of resources present "threats" of harm that a person feels compelled to prevent at all costs.

Persons sometimes accept offers that they would refuse under less constraining circumstances, and the offer of money for a kidney seems a prime example. Such an offer may be exploitative in the sense that it manipulates a person into an unwelcome choice through incentives too attractive to be refused by the person. The prospect of another shivering night in the cold, another day without decent food, or another visit from a debt collector could place enormous pressure on a person to accept an offer of payment for a kidney, just as would an intentional threat by an employer to fire an employee who could not find another job unless the employee agreed to be transferred to an objectionable location and position. The psychological effects on persons constrained to choose payment for a kidney and to accept relocation in a job may be similar, and the person can appropriately say in each case: "I have no choice; it is not feasible to refuse the offer".

If payments for kidneys were excessively large or even high enough to attract persons from all classes in society, the payments likely would be judged overly powerful inducements for impoverished persons attracted to the payments. Alternatively, if the rate of pay were exceptionally low, kidney "donors" likely would be recruited entirely from the ranks of the unemployed and impoverished. The objective of a just payment scheme would be to strike a balance between irresistible inducement and underpayment. This goal may be achievable, but there is no a priori way to set an appropriate payment level, and discerning management of a market in kidneys would be demanding.

This issue rests in part on difficulties in determining the threshold of irresistible offers (those that manipulate and render choice less than adequately autonomous). An offer that manipulates one person into acceptance may either fail to be irresistible to another or be a welcome (rather than unwelcome) offer. How an offer is perceived and whether it will be accepted depend on the subjective responses of the persons who receive the offer. On the one hand, a subjective standard for warranted offers would be very difficult to imple- ment as a policy governing a market in kidneys, because officials would have to determine how each individual is affected by an offer. On the other hand, it would be morally perilous to use an objective standard based on the irresistibility of offers to the average, or ordinary, or reasonable person. This standard would fail to protect the most vulnerable of the vulnerable.

\section{Can kidney sales be justified?}

How powerful are the two arguments from exploitation that I have presented? These arguments raise profound questions about just markets and just offers, but I do not think that they are strong enough to uphold a ban on kidney sales under all circumstances. Other moral considerations must be considered.

Even if those who sell their kidneys are at risk of exploitation in the respects I have identified, it does not follow that a ban on the sale of kidneys is the best way to address these problems. Some volunteers will find the offers welcome, and the consents of many volunteers will be substantially autonomous. They may see a kidney sale as their best option, all things considered. To protect them from an unjust system by banning the sale of their kidneys could make life worse for them, and render them more rather than less vulnerable. (See also the arguments favouring sales in Radcliffe-Richards, et al. ${ }^{27}$ )

There are already many unfairnesses in our systems of health care that privilege the wealthy and effectively preclude benefits from flowing to the poor. We do not ban these privileges in the context of a free market economy; rather, we seek to improve the justice of the system. It is far from clear that kidney sales should be considered relevantly different, and we risk coherence in the attempt. A policy of banning sales may also cause us to neglect the deepest concern of justice that I have put forward, which is how to render the system of kidney procurement fair for all parties involved. The current system is, by all accounts, a shameful failure. A ban on sales could work as an excuse for neglect of the real injustices in our systems of procurement and distribution.

We ought not to assume that a fair system of incentives or payments for kidneys cannot be constructed. Perhaps we can devise a system of national committees and regulatory agencies that is capable of monitoring each sale or incentive structure and that appropriately rewards those who respond to an incentive. (See also the assessments of problems and possibilities in Rothman, et al. ${ }^{28}$ ) At least some governments may be able to administer a market in which a fair and nonexploitative price is paid, while avoiding exploitative private markets and black markets. Even if the prospects are dim at the present time for a just system of procurement and distribution that includes incentives for kidneys, we should be working to decrease rather than increase the injustice of our policies. The current system seems to me to fail this test at virtually every level.

\section{REFERENCES}

1 Beauchamp TL, Childress J. Principles of biomedical ethics. New York: Oxford University Press, 1st ed, 1979; 5th ed, 2001.

2 Rawls J. A theory of justice. Cambridge, MA: Harvard University Press, 1971: 20ff, 46-50, 579-80; rev ed, 1999: 17ff, 40-45, 508-9.

3 Rawls J. Political liberalism. New York: Columbia University Press, 1996: 8, 381, 384, and 399

4 Rawls J. The independence of moral theory. Proceedings and Addresses of the American Philosophical Association 1974-75;48:8.

5 Richardson H. Specifying norms as a way to resolve concrete ethical problems. Philos Public Aff 1990;19:279-310.

6 Richardson H. Specifying, balancing, and interpreting bioethical principles. J Med Philos 2000;25:285-307.

7 DeGrazia D. Moving forward in bioethical theory: theories, cases, and specified principlism. J Med Philos 1992;17:511-39.

8 DeGrazia D, Beauchamp TL. Philosophical foundations and philosophical methods. In: Sulmasy D, Sugarman J, eds. Methods of bioethics. Washington: Georgetown University Press, 2001:33-6. 
9 Jonsen AR, Toulmin S. The abuse of casuistry: a history of moral reasoning. Berkeley: University of California Press, 1988:1 1-19, 25 1-4, 296-9

10 Jonsen AR. Casuistry as methodology in clinical ethics. Theor Med 1991:12:299-302.

11 Arras J. Principles and particularity: the role of cases in bioethics. Indiana Law J 1994;69:983-1014.

12 Arras J. A case approach. In: Kuhse H, Singer P, eds. A companion to bioethics. Oxford: Blackwell Publishers, 1998: 106-13, especially $112-13$.

13 Gillon R. Four scenarios. J Med Ethics 2003;29:267-8.

14 Kuflik A. The inalienability of autonomy. Philos Public Aff 1984; 13:271-98.

15 Raz J. Authority and justification. Philos Public Aff 1985;14:3-29.

16 McMahon C. Autonomy and authority. Philos Public Aff 1987;16: 303-28.

17 Stanfield J. Current public law and policy issues: faith healing and religious treatment exemptions to child endangerment laws. Hamline Journal of Public Law and Policy 2000;22:45-86.

18 Prince v Massachusetts 321 US 158 (1944).

19 Garner BA, Campbell H, eds. Black's Law Dictionary. St Paul's, MN: West Group.
20 Delmonico FL, Arnold R, Scheper-Hughes N, et al. Ethical incentives - not payment-for organ donation. N Engl J Med 2002;346:2002-5.

21 Arnold R, Bartlett S, Bernat J, et al. Financial incentives for cadaver organ donation: an ethical reappraisal. Transplantation 2002:73:1361-7.

22 Gill MB, Sade RM. Paying for kidneys: the case against prohibition. Kennedy Inst Ethics J 2002; 12:17-45.

23 Joralemon D, Cox P. Body values: the case against compensating for transplant organs. Hastings Cent Rep 2002;33:17-33.

24 Online shoppers bid millions for human kidney. www. CNN.com (accessed 3 Sept 1999).

25 Goyal M, Mehta RL, Schneiderman L, et al. Economic and health consequences of selling a kidney in India. JAMA 2002;288:1589-93.

26 Cohen L. Where it hurts: Indian material for an ethics of organ transplantation. Daedalus 1999;128:135-65.

27 Radcliffe-Richards J, Daar AS, Guttmann RD, et al. International Forum for Transplant Ethics. The case for allowing kidney sales. Lancet 1998;351:1950-2.

28 Rothman DJ, Rose E, Awaya T, et al. The Bellagio task force report on transplantation, bodily integrity, and the international traffic in organs. Transplant Proc 1997;29:2739-45.

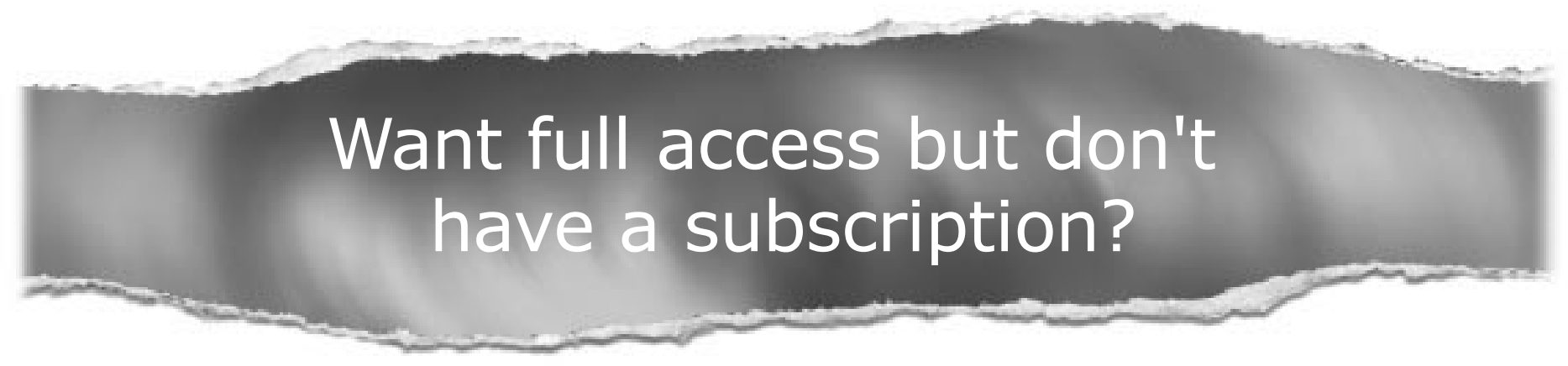

\section{Pay per access}

For just US $\$ 25$ you can have instant access to the whole website for 30 days. During this time you will be able to access the full text for all issues (including supplements) available. You will also be able to download and print any relevant pdf files for personal use, and take advantage of all the special features the Journal of Medical Ethics online has to offer. 